\title{
Commentary: Adaptive from innate: Human IFN- -+ CD4 + T cells can arise directly from CXCL8-producing recent thymic emigrants in babies and adults
}

\author{
Deena L. Gibbons ${ }^{1 *}$ and Paul Fleming ${ }^{2}$ \\ 'Peter Gorer Department of Immunobiology, School of Immunology and Microbial Sciences, Kings College London \\ ${ }^{2}$ Department of Neonatology, Homerton University Hospital NHS Foundation Trust, London
}

Article Info

\section{Article Notes}

Received: October 01, 2017

Accepted: October 25, 2017

\section{*Correspondence:}

Dr. Deena L. Gibbons, Peter Gorer Department of Immunobiology, School of Immunology and Microbial Sciences, Kings College London, London SE1 9RT, United Kingdom, E-mail: deena.gibbons@kcl.ac.uk.

( 2017 Gibbons DL. This article is distributed under the terms of the Creative Commons Attribution 4.0 International License.

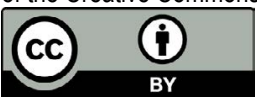

This paper, ${ }^{1}$ in the Journal of Immunology, follows up from our pivotal paper published in Nature Medicine in $2014^{2}$. The original paper identified that a substantial proportion of $\mathrm{CD} 4^{+} \mathrm{T}$ cells from human newborn babies (both preterm and term infants) respond to activation by expressing high levels of CXC-chemokine ligand 8 (CXCL8; also known as IL-8), a phenomenon not usually seen in adults. The abundance of these CXCL8-producing $\mathrm{CD}^{+} \mathrm{T}$ cells in infants suggested a potential role for these cells in immune defence. This was novel, as $\mathrm{T}$ cells from the newborn were previously regarded as anti-inflammatory ${ }^{3}$. In support of this concept, we identified that spontaneous T cell production of CXCL8 was associated with episodes of neonatal infection in vivo and an enhanced ability to produce CXCL8 was observed in patients with elevated CRP2. This suggested that the infant immune system may not be solely antiinflammatory (as had been the previous dogma). Instead, neonatal $\mathrm{T}$ cells could possess important anti-bacterial functions such as attracting and activating polymorphonuclear neutrophils (PMNs)-a known function of CXCL8.

A key question raised by this previous finding was whether or not, the CXCL8-producing CD4 ${ }^{+} \mathrm{T}$ cell was specific to newborn babies, consistent with the idea that the foetal $\mathrm{T}$ cell represents a unique cell lineage compared to the adult $\mathrm{T}$ cell ${ }^{4}$. Alternatively, could newly-arising $\mathrm{CD} 4^{+} \mathrm{T}$ cells in adult humans likewise produce CXCL8? Our most recent paper answered this question. By analysing a wide range of samples from adult humans, the authors show that CXCL8producing $\mathrm{T}$ cells can still be detected, though their numbers are dramatically reduced. CXCL8 producing cells that were identified, expressed significantly more $\mathrm{T}$ cell receptor (TCR) excision circles (TRECs) than non-CXCL8 producing cells. TRECs are small, stable, excised circles of DNA created during the process of TCR gene rearrangement in the thymus. As they become diluted out during cell division, the expression of TRECs identifies these as cells having recently exited the thymus and hence are more commonly known as recent thymic emigrants (RTEs). Hence, whereas the initial data suggested the ability of CD4 T cells to produce CXCL8 may have been a neonatal specific phenomenon, the low abundance of this cell in adults is actually related to thymic atrophy with age and not due to an inherent difference between the two immune systems. The concept that CXCL8-production is a feature of recent 
thymic emigration is consistent with the diminished CXCL8 production observed in children following thymectomy ${ }^{5}$. Indeed, these cells were also identified during the immune reconstitution that occurred following $\mathrm{T}$ cell depletion by alemtuzumab (anti-CD52) during treatment for multiple sclerosis ${ }^{6}$. The latter study also suggested that these CXCL8-producing RTEs express the complement receptors, CR1 and CR $2^{6}$ potentially conferring upon them, the ability to act and respond similarly to innate immune cells.

The ability to produce CXCL8 was observed in developing $\mathrm{T}$ cells in the thymus. Interestingly, a larger percentage of $\mathrm{CD}_{4}^{+}$RTEs expressed CXCL8 than their paired CD4 ${ }^{+}$ thymocyte counterparts. This suggests that CXCL8 is either a marker of thymic competence or, perhaps more likely, that CXCL8 production is of functional importance to the newly-egressed $\mathrm{T}$ cell. Thus, cells capable of its production are enriched amongst those cells that are exported to the periphery. The capacity of a $\mathrm{T}$ cell to deliver effector function prior to differentiation would seem a highly efficient way to protect newborn babies (in whom RTEs are preferentially enriched) against invading bacteria. So, what happens to these CXCL8-producing CD4 cells over time? This paper, together with previously published work $^{5,7}$, showed that TCR activation and/or cytokine induced proliferation of bulk human CXCL8-producing cells could give rise to IFN$\gamma$-producing cells in vitro. However, as the analysis was not undertaken at a single cell level, the direct conversion of a CXCL8-producing cell into one that produced IFN- $\gamma$ could not be distinguished from the outgrowth of existing IFN- $\gamma$ producing cells. To get around this issue, we sorted individual CXCL8-producing cells and then cloned them to identify their direct progeny. TCR sequencing verified that $\mathrm{CXCL8}^{+} \mathrm{CD}^{+} \mathrm{T}$ cells isolated from either newborn babies or adults can serve as direct precursors of human IFN- $\gamma$-producing CD4+ Th1 cells. Thus, the most naïve peripheral T cells (RTEs) in adults as well as in babies have the potential for CXCL8 production, but this ability then rapidly converts to conventional IFN$\gamma$-producing CD4+ ${ }^{+}$Th1 cells. What was not identified in this paper was the precise mechanism responsible for this 'innate to adaptive' switch. If indeed the CXCL8-producing T cell is affording the infant some protection against potentially pathogenic organisms, then their conversion to IFN- $\gamma$ producing $\mathrm{CD} 4^{+} \mathrm{Th} 1$ cells must be carefully controlled so as to avoid potential acute immunodeficiency, a phenomenon that may occur if the available pool of CXCL8 producing cells were rapidly depleted. Alternatively, deleterious pathology in the infant (for example, the overwhelming systemic inflammatory response seen in conditions like necrotising enterocolitis with which CXCL8 has been associated ${ }^{8,9,10,11}$ may be a consequence of an exaggerated functional response by the CXCL8-producing T cell. In this latter scenario a more rapid conversion of CXCL8 cells to classical Th1 cells might be beneficial.
It should be noted that although only IFN- $\gamma$-producing cells were generated from the CXCL8-producing precursor cell in our study, the experiments undertaken did not preclude the development of other classic adaptive lineages (eg TH2/Th17) from the CXCL8-producing precursor, or indeed the development of dual IFN- $\gamma /$ IL17 producers. Gene expression data suggested that Th1 skewing was the most likely outcome as there was a strong correlation between CXCL8 and EGR1 gene expression, where EGR1 regulates the Th1 driving transcription factor, T-bet. Different polarising conditions would be required to fully identify all of the potential fates of CXCL8-producing RTEs.

In summary, these data shed more light on the CXCL8producing $\mathrm{T}$ cell with novel insights into human $\mathrm{T}$ cell ontogeny. It shows that conventional adaptive lymphocyte immunity can arise from innate-like developmental intermediates with intrinsic functional potential rather than from functionless $T$ cell progenitors (Th0 cells), which was previously considered the norm. Thus, this highlights a novel functional intermediate during the transition to classic adaptive immunity (eg Th1). More work is needed to fully understand the role of the CXCL8-producing $\mathrm{T}$ cell in protecting the newborn baby from infection whilst preventing uncontrolled activation of these cells which, in theory, could explain the exaggerated immune response associated with common neonatal proinflammatory diseases.

${ }^{1}$ To whom correspondence should be addressed: deena. gibbons@kcl.ac.uk

\section{References}

1. Das A, Rouault-Pierre K, Kamdar S, et al. Adaptive from Innate: Human IFN-gamma+CD4+ T Cells Can Arise Directly from CXCL8-Producing Recent Thymic Emigrants in Babies and Adults. J Immunol. 2017; 199: 1696-1705. doi:10.4049/jimmunol.1700551.

2. Gibbons D, Fleming P, Virasami A, et al. Interleukin-8 (CXCL8) production is a signatory $\mathrm{T}$ cell effector function of human newborn infants. Nat Med. 2014; 20: 1206-1210. doi:10.1038/nm.3670.

3. Adkins B, Leclerc C, Marshall-Clarke S. Neonatal adaptive immunity comes of age. Nat Rev Immunol. 2004; 4: 553-564. doi:10.1038/ nri1394.

4. Mold JE, Venkatasubrahmanyam S, Burt TD, et al. Fetal and adult hematopoietic stem cells give rise to distinct $\mathrm{T}$ cell lineages in humans. Science. 2010; 330: 1695-1699. doi:10.1126/science.1196509.

5. van den Broek T, Delemarre EM, Janssen WJ, et al. Neonatal thymectomy reveals differentiation and plasticity within human naive T cells. J Clin Invest. 2016; 126: 1126-1136. doi:10.1172/JCI84997.

6. Pekalski ML, García AR, Ferreira RC, et al. Neonatal and adult recent thymic emigrants produce IL- 8 and express complement receptors CR1 and CR2. JCI Insight. 2017; 2. doi:10.1172/jci.insight.93739.

7. Akhade AS, Qadri A. T-cell receptor activation of human CD4(+) T cells shifts the innate TLR response from CXCL8(hi) IFN-gamma(null) to CXCL8(lo) IFN-gamma(hi). Eur J Immunol. 2015; 45: 2628-2637. doi:10.1002/eji.201545553.

8. Benkoe $\mathrm{T}$, Reck $\mathrm{C}$, Pones $\mathrm{M}$, et al. Interleukin-8 predicts 60-day mortality in premature infants with necrotizing enterocolitis. J Pediatr Surg. 2014; 49: 385-389. doi:10.1016/j.jpedsurg.2013.05.068. 
9. Benkoe TM, Mechtler TP, Weninger M, et al. Serum levels of interleukin-8 and gut-associated biomarkers in diagnosing necrotizing enterocolitis in preterm infants. J Pediatr Surg. 2014; 49: 1446-1451. doi:10.1016/j.jpedsurg.2014.03.012.

10. Maheshwari A, Schelonka RL, Dimmitt RA, et al. Cytokines associated with necrotizing enterocolitis in extremely-low-birth-weight infants. Pediatr Res. 2014; 76: 100-108. doi:10.1038/pr.2014.48.

11. Cho SX, Berger PJ, Nold-Petry CA, et al. The immunological landscape in necrotising enterocolitis. Expert Rev Mol Med. 2016; 18: e12. doi:10.1017/erm.2016.13. 